\title{
Silver-Coated Endotracheal Tubes Cleaned With a Mechanism for Secretion Removal
}

\author{
Massimiliano Pirrone, David AE Imber, Francesco Marrazzo, Riccardo Pinciroli, \\ Changsheng Zhang, Lynn Bry, Mary L Delaney, Andrea M Dubois, John G Thomas, \\ Laura Nistico, Rachael Melton-Kreft, Edward A Bittner, Robert M Kacmarek, and Lorenzo Berra
}

\begin{abstract}
BACKGROUND: Biofilm on the surface of endotracheal tubes (ETTs) is associated with ventilatorassociated pneumonia. The use of silver-coated ETTs has been suggested to reduce the occurrence of ventilator-associated pneumonia by preventing biofilm formation. However, mucus accumulation can reduce the antibacterial activity of silver-coated ETTs by isolating bacterial colonies from the silver surface. We hypothesized that, in mechanically ventilated subjects, periodic removal of secretions through the use of a cleaning device would enhance the antimicrobial properties of silver-coated ETTs and thus reduce bacterial colonization. METHODS: Subjects were randomized to either standard suctioning (blind tracheal suctioning, control group) or blind tracheal suctioning plus cleaning maneuver every $8 \mathrm{~h}$ (treatment group). Tracheal aspirates were collected immediately before extubation for microbiological culture. After extubation, ETTs were collected for both cultural and non-cultural microbiological analysis and biofilm isolation. RESULTS: 39 subjects expected to be ventilated for $>48 \mathrm{~h}$ were enrolled; 36 ETTs (18 control, 18 treatment) and 29 tracheal samples (15 control, 14 treatment) were collected. Among the ETTs positive for bacterial colonization (15 vs $9, P=.18$ ), cleaning maneuvers did not reduce microbial load, shown as the decimal logarithm of colony-forming units (CFU) per $\mathrm{mL}(1.6 \pm 1.2 \mathrm{vs} 0.9 \pm 1.2 \log \mathrm{CFU} / \mathrm{mL}$, $P=.15)$. There was a trend toward decreased biofilm deposition $(439.5 \pm 29.0 \mathrm{vs} 288.9 \pm 157.7 \mathrm{mg}$, $P=.09)$ in the treated ETTs. No significant differences were observed in the number of positive tracheal aspirates $(13 \mathrm{vs} 10, P=.39)$ or in the microbial load $(4.8 \pm 4.0 \mathrm{vs} 4.2 \pm 3.8 \log \mathrm{CFU} / \mathrm{mL}$, $P=.70)$ of tracheal secretions. Finally, no differences in the microbial load of Gram-positive organisms, Gram-negative organisms, or yeasts were found between the ETTs and tracheal aspirates of the 2 groups. CONCLUSIONS: In 39 critically-ill subjects intubated with silver-coated ETTs, periodic cleaning maneuvers did not decrease bacterial colonization of the ETTs and did not lower respiratory tract colonization compared to the standard suctioning. (Clinicaltrials.gov registration NCT02120001.) Key words: intubation; ventilation; biofilms; pneumonia; ventilator-associated pneumonia; airway obstruction; airway management. [Respir Care 2019;64(1):1-9. (C) 2019 Daedalus Enterprises]
\end{abstract}

Introduction

The growth of biofilm on the inner surface of endotracheal tubes (ETTs) has been recognized as one of the key

\footnotetext{
Drs Pirrone, Marrazzo, Pinciroli, Zhang, Bittner, Kacmarek, and Berra, as well as Mr Imber, are affiliated with the Department of Anesthesia, Critical Care and Pain Medicine, Massachusetts General Hospital, Boston, Massachusetts. Dr Pirrone is affiliated with the Department of Anesthesia and Critical Care, Fondazione IRCCS Ca' Granda Ospedale Maggiore Policlinico, University of Milan, Italy. Dr Pinciroli is also
}

steps that lead to the development of ventilator-associated pneumonia (VAP). ${ }^{1-4}$ ETTs become heavily colonized with secretions after a relatively short time compared to the average intubation time of critically ill patients, represent- 


\section{Secretion Removal in Silver-Coated ETTs}

ing a continuous source of bacterial exposure of the lower respiratory system. ${ }^{5-7}$

\section{See the Related Editorial on Page 108}

In recent years, methods have been developed to mechanically remove secretions from the inner lumen of ETTs ${ }^{8-10}$ and to reduce biofilm formation by applying a variety of bactericidal or bacteriostatic agents to the surface of the ETTs through coating or intrusion techniques. ${ }^{11,12}$ In one large, randomized, multi-center, clinical trial in the United States, silver-coated ETTs slightly decreased the incidence of the early-onset VAP compared to uncoated tubes $(4.8 \%$ vs $7.5 \%, P=.03) .{ }^{13}$ However, in other clinical and animal studies in which the surface of the ETTs were analyzed after a few days of mechanical ventilation, bacterial colonies were always present regardless of the antibacterial coating and methods applied, suggesting that mucus and exopolysaccaride deposition may form a barrier isolating the bacterial communities from the antibacterial surface. ${ }^{10,11,14-16}$ By removing secretions from the ETT surface, we were able to retain the bactericidal activity of coated ETTs in healthy sheep that were mechanically ventilated for up to 168 h. $^{14}$

We conducted this study in critically ill subjects emergently intubated to test the hypothesis that keeping the inner surface of silver-coated ETTs free from biofilm and secretions would improve the effectiveness of silver-coated ETTs. We evaluated the efficacy of a specific ETT cleaning device (endOclear, Endoclear, Petoskey, Michigan) in preserving the microbicidal properties of commercially available silver-coated ETTs. ${ }^{17}$ Our primary end point was the detection of a difference in microbial colonization on silver-coated ETTs in the treatment group, which received surface cleaning with the endOclear device.

Excellence in Biofilm Research, Pittsburgh, Pennsylvania. Dr Kacmarek is also affiliated with the Department of Respiratory Care, Massachusetts General Hospital, Boston, Massachusetts.

Dr Pirrone presented a version of this paper at the Society of Critical Care Medicine Congress, held January 17-21, 2015, in Phoenix, Arizona.

Dr Kacmarek discloses relationships with Covidien, Orange Medical, and Venner Medical. Dr Berra discloses relationships with endOclear LLC, Venner Medical, and the National Institutes of Health. The other authors have disclosed no conflicts of interest.

Correspondence: Lorenzo Berra, Department of Anesthesia, Critical Care and Pain Medicine, Massachusetts General Hospital. White 434-B, 55 Fruit Street, Boston, MA 02114. E-mail: lberra@mgh.harvard.edu.

DOI: $10.4187 /$ respcare.06222

\section{QUICK LOOK}

\section{Current knowledge}

The antibacterial nature of silver-coated endotracheal tubes (ETTs) is compromised by mucus accumulation. Blind tracheal suctioning does not effectively clear secretions. The use of a wiper-cleaning device may help reduce microbial colonization by improving mucus clearance.

\section{What this paper contributes to our knowledge}

Wiping secretions away with cleaning maneuvers did not decrease microbial colonization on ETTs or in the lower respiratory tract as compared to standard blind tracheal suctioning in 39 subjects intubated with silvercoated ETTs.

\section{Methods}

The study was conducted in medical, surgical, and neurological ICUs at Massachusetts General Hospital, and it was approved by the local Institutional Review Board. Patients who required the in-hospital emergency airway team were intubated with a commercially available, $7.0-\mathrm{mm}$ inner diameter, silver-coated ETT (Agento I.C. silvercoated, C.R. Bard, Covington, Georgia). Adult patients who were expected to remain intubated for at least $48 \mathrm{~h}$ and could be enrolled within $24 \mathrm{~h}$ afater intubation were considered eligible for the study. After informed consent was obtained from the patients or a surrogate, subjects were randomized through sealed envelopes in a 1:1 ratio to receive either standard airway care (blind suctioning) or blind suctioning plus the cleaning maneuver every $8 \mathrm{~h}$. The cleaning maneuver consisted of a single pass of the endOclear device through the ETT, as described in our previous study. ${ }^{18}$ Subjects of both groups were cared for according to the VAP-prevention bundle, ${ }^{19}$ and ETT cuff pressure was checked every $8 \mathrm{~h}$, with the goal to maintain cuff pressure at $25 \mathrm{~cm} \mathrm{H}_{2} \mathrm{O}$ or to match peak pressure if $>25 \mathrm{~cm} \mathrm{H}_{2} \mathrm{O}$. Immediately before extubation, a sample of tracheal secretions was obtained with a sterile mucus trap. Silver-coated tubes were immediately collected at extubation, with the proximal end clamped below the plastic connector and the distal end clamped immediately above the Murphy's eye. The tubes were placed in a sterile bag for microbiological analysis and further processing.

\section{ETT Processing}

Collected tubes were handled in a sterile environment. The distal end was cut with a scalpel above the Murphy's 


\section{Secretion Removal in Silver-Coated ETTs}

eye, and a $0.5-\mathrm{cm}$ slice of the tube was collected for culture-independent microbiological analysis. After collecting the ETT slice, the tubes were filled with $10 \mathrm{~mL}$ sterile $0.1 \%$ solution of sodium thioglycolate and phosphatebuffered saline for silver ion inactivation and biofilm collection and sealed. ${ }^{20}$ ETTs were placed in a sonication bath for $90 \mathrm{~s}$ and then vortexed for an additional $30 \mathrm{~s}$. The phosphate-buffered saline-biofilm suspension was then stored in a Falcon vial and sent to the laboratory for microbiological culture.

\section{Biofilm Mass}

Biofilm mass inside the ETT was obtained as the difference between the weight of the collected tube and the weight of the ETT after biofilm collection, as described previously. ${ }^{18}$ Tubes were weighed 3 times with a high-precision scale (PW124, Adam Equipment, Denbigh, United Kingdom), and the 3 results averaged.

\section{Culture-Independent Analysis and Confocal Laser Scanning Microscopy}

For 10 tubes (5 from each group), an additional $0.5-\mathrm{cm}$ slice was cut immediately before the phosphate-buffered saline wash for culture-independent microbiological analysis. Using unused sterile equipment washed thoroughly with sterile gauze soaked in $70 \%$ ethanol, the slice was collected from the distal section of the tube, above the Murphy's eye, and placed in a sterile, DNA-free vial containing $10 \mathrm{~mL}$ RNALATER (Life Technologies, Carlsbad, California). Samples where frozen at $-80^{\circ} \mathrm{C}$ and sent to the microbiology lab. The ETT slices were visualized with confocal laser scanning microscopy ${ }^{21}$ and $16 \mathrm{~S}$ species-specific fluorescent in situ hybridization. ${ }^{22,23}$

\section{Sample Size and Statistical Analysis}

The primary end point of this study was the detection of a greater reduction in microbial ETT colonization on silver-coated ETTs in the treatment group due to the cleaning maneuver. In a prior study, we showed that standard noncoated ETTs cleaned with the endOclear were colonized by pathogens expressed as the decimal logarithm of colonyforming units (CFU) per $\mathrm{mL}(2.85 \pm 0.49 \log \mathrm{CFU} / \mathrm{mL}) .^{14,18,20}$ Given our hypothesis of a synergistic effect between the 2 devices, we expected ETTs in the treatment group to show an average reduction of $0.5 \log \mathrm{CFU} / \mathrm{mL}$ compared to silver ETTs without endOclear cleaning. We calculated that 32 subjects (16 for each group) should be enrolled to detect a mean difference for a statistical power of $80 \%$ with a 2-sided significance level of 0.05 in a 2-sample $t$ test for mean difference.

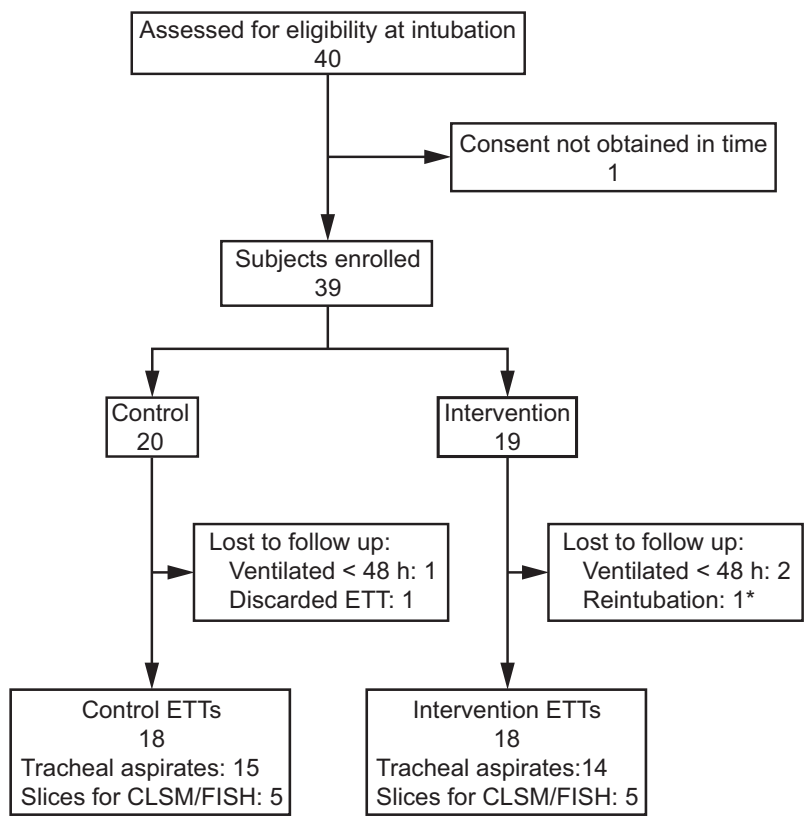

Fig. 1. Flow chart. ETT = endotracheal tube; CLSM = confocal laser scanning microscopy; FISH = fluorescent in-situ hybridization. * Subject was reintubated in the ICU and completed the study twice; for this subject 2 ETTs were collected.

Continuous variables are expressed as mean $\pm \mathrm{SD}$ or median (interquartile range), as appropriate. Normality of data distribution was assessed with the Shapiro-Wilk test. Differences in quantitative variables between the treatment and control groups were tested using the $t$ test or the Mann-Whitney test, as appropriate. Categorical variables were tested using the Fisher exact test. $P<.05$ was considered statistically significant.

\section{Results}

Out of 40 consecutive eligible patients, 39 subjects were enrolled (20 vs 19 , control vs treatment group) because informed consent could not be obtained for 1 patient within $24 \mathrm{~h}$ from the time of intubation. After randomization, a total of 3 subjects ( 1 in the control group, 2 in the treatment group) could not complete the study because they were intubated for $<48 \mathrm{~h}$. One ETT from the control group was accidentally discarded by the clinical staff and could not be processed; 1 subject from the treatment group was reintubated, and both ETTs were included in the analysis. As a result, 18 ETTs per group were studied for the primary end point analysis (Fig. 1). Slices from a total of 10 ETTs (5 from the control group, 5 from the treatment group) were sent for culture-independent microbiological analysis. Among them, the 4 most representative samples (2 from each group) were selected for confocal laser scanning microscopy and fluorescent in situ hybridization processing. The characteristics of our study population are 


\section{Secretion Removal in Silver-Coated ETTs}

Table 1. Description of Study Population

\begin{tabular}{|c|c|c|c|}
\hline & Control & Treatment & $P$ \\
\hline Age, y & $61.2 \pm 3.5$ & $65.6 \pm 4.1$ & .42 \\
\hline Female, $n(\%)$ & $10(53)$ & $4(24)$ & .10 \\
\hline Body mass index, $\mathrm{kg} / \mathrm{m}^{2}$ & $27.8 \pm 1.4$ & $27.2 \pm 2.1$ & .84 \\
\hline SAPS II score & $40.8 \pm 1.9$ & $38.4 \pm 2.6$ & .45 \\
\hline \multicolumn{3}{|l|}{ Admission to ICU, $n(\%)$} & .66 \\
\hline Medical & $14(74)$ & $15(88)$ & \\
\hline Scheduled surgery & $4(21)$ & $2(12)$ & \\
\hline Emergency surgery & $1(5)$ & $0(0)$ & \\
\hline \multicolumn{3}{|l|}{ Reason for intubation, $n(\%)$} & .30 \\
\hline Airway protection & $14(74)$ & $16(94)$ & \\
\hline Respiratory failure & $2(10)$ & $1(6)$ & \\
\hline Neurologic failure & $3(16)$ & $0(0)$ & \\
\hline Previously intubated, $n(\%)$ & $7(37)$ & $3(18)$ & .27 \\
\hline \multicolumn{4}{|l|}{ Comorbidities, $n(\%)$} \\
\hline Current smokers & $0(0)$ & $1(0)$ & .47 \\
\hline COPD, asthma, bronchiectasis & $6(32)$ & $7(41)$ & .73 \\
\hline Diabetes & $4(21)$ & $3(18)$ & $>.99$ \\
\hline Duration of intubation, $\mathrm{d}$ & $6.9 \pm 0.9$ & $5.8 \pm 0.9$ & .36 \\
\hline \multicolumn{4}{|c|}{$\begin{array}{l}\text { Values are presented as mean } \pm \text { SD or } n(\%) \text {. } \\
\text { Control group, } n=19 \text { subjects; Treatment group, } n=17 \text { subjects. } \\
\text { SAPS = Simplified Acute Physiology Score }\end{array}$} \\
\hline
\end{tabular}

shown in Table 1. No significant differences were observed between the 2 groups at baseline.

\section{ETT Colonization}

The amount of biofilm deposition was $<0.5 \mathrm{~g}$ and did not significantly differ between the control group and the treatment group $(439.5 \pm 29.0 \mathrm{mg}$ vs $288.9 \pm 157.7 \mathrm{mg}$, $P=.09$ ) (Table 2). Fewer ETTs from the treatment group tested positive for microbial growth, but the difference did not reach statistical significance (15 tubes from the control group vs 9 tubes from the treatment group, $P=.18)$. In both groups, the most represented groups of microbes were yeast (11 tubes from the control group, 6 tubes from the treatment group, $P=.31$ ), followed by Gram-positive bacteria ( 9 tubes from the control group, 6 tubes from the treatment group, $P=.67)$. Gram-negative species were the least present in both groups (5 tubes from the control group, 2 tubes from the treatment group, $P=.60$ ). Nine tubes from the control group and 7 tubes from the treatment group showed multiple species of bacterial growth $(P=.73)$ (Fig. 2A), with an average number of isolated species per tube of $1.6 \pm 1.2$ in the control group and $1.1 \pm 1.2$ in the treatment group $(P=.22)$. Total microbial load was not significantly different between the control and treatment groups $(1.6 \pm 1.2$ in the control group vs $0.9 \pm 1.2$ in the treatment group, $P=.15)$, and there was no difference between Gram-positive (control $1.3 \pm 2.0$ vs treatment $1.2 \pm 1.9, P=.80)$, Gram-
Table 2. Tracheal Tube Colonization

\begin{tabular}{|c|c|c|c|}
\hline & Control & Treatment & $P$ \\
\hline Amount of biofilm & $439.5 \pm 29.0$ & $288.9 \pm 157.7$ & .09 \\
\hline Colonized tubes, no. (\%) & $15(83)$ & $9(50)$ & .18 \\
\hline Gram-positive & $9(50)$ & $6(33)$ & .67 \\
\hline Gram-negative & $5(27)$ & $2(11)$ & .60 \\
\hline Yeasts & $11(61)$ & $6(33)$ & .31 \\
\hline Multiple species present & $9(50)$ & $7(39)$ & .73 \\
\hline $\begin{array}{l}\text { Number of species isolated } \\
\text { per tube }\end{array}$ & $1.6 \pm 1.2$ & $1.1 \pm 1.2$ & .22 \\
\hline Total microbial load, logCFU/mL & $1.6 \pm 1.2$ & $0.9 \pm 1.2$ & .15 \\
\hline Gram positive, $\log \mathrm{CFU} / \mathrm{mL}$ & $1.3 \pm 2.0$ & $1.2 \pm 1.9$ & .80 \\
\hline Gram negative, $\log \mathrm{CFU} / \mathrm{mL}$ & $0.5 \pm 0.9$ & $0.5 \pm 1.6$ & .94 \\
\hline Yeasts, $\log \mathrm{CFU} / \mathrm{mL}$ & $1.8 \pm 1.8$ & $1.0 \pm 2.2$ & .24 \\
\hline $\begin{array}{l}\text { Values are presented as mean } \pm \text { SD or no. (\% } \\
\text { Control group, } n=18 \text { subjects; Treatment gro } \\
\text { Gram-positive species = Enterobacteriaceae, } \\
\text { Staphylococcus } \text { spp., Streptococcus spp., Lacto } \\
\text { Gram-negative species = Escherichia coli, Ent } \\
\text { Moraxella catarrhalis, Pseudomonas fluoresce } \\
\text { Yeasts = Candida tropicalis, Candida albican } \\
\text { CFU = colony-forming unit }\end{array}$ & $\begin{array}{l}\text { up, } n=18 \text { subjects. } \\
\text { orynebacterium spp } \\
\text { bacillum spp. } \\
\text { erobacter aerogenes } \\
\text {, Candida parapsilo }\end{array}$ & $\begin{array}{l}\text {., Staphylococcus aur } \\
\text { Klebsiella pneumoni } \\
\text { sis, Candida glabra }\end{array}$ & \\
\hline
\end{tabular}

negative (control $0.5 \pm 0.9$ vs treatment $0.5 \pm 1.6$, $P=.94$ ), and yeast microbial load (control $1.8 \pm 1.8 \mathrm{vs}$ treatment $1.0 \pm 2.2, P=.24)$ between the control and treatment groups.

\section{Colonization of Secretions}

A total of 29 tracheal samples were obtained before extubation (15 samples from control group, 14 samples from treatment group) (Table 3 ). There was no difference in the number of subjects who tested positive for microbial presence in tracheal secretions (13 in the control group, 10 in the control group, $P=.39$ ), and there was no difference in Gram-positive ( 6 in the control group, 6 in the treatment group, $P>.99$ ), Gram-negative (1 in the control group, 2 in the treatment group, $P=.60$ ), or yeast colonization of the airway (11 in the control group, 7 in the treatment group, $P=.26$ ). The number of tracheal secretions with multiple microbial species was not different (6 in the control group, 8 in the treatment group $P=.71$ ) (Fig. 2B), and the average number of microbial species per sample was similar between the 2 groups $(1.5 \pm 1.2$ in the control group, $1.6 \pm 1.6$ in the treatment group, $P=.79$ ). The total microbial load was higher in the airway, as determined with culture of tracheal secretions taken immediately before extubation, than in the ETT and did not differ between treatment and control groups $(4.8 \pm 4.0$ $\log \mathrm{CFU} / \mathrm{mL}$ in the control group, $4.2 \pm 3.8 \log \mathrm{CFU} / \mathrm{mL}$ in the treatment group, $P=.70$ ). 

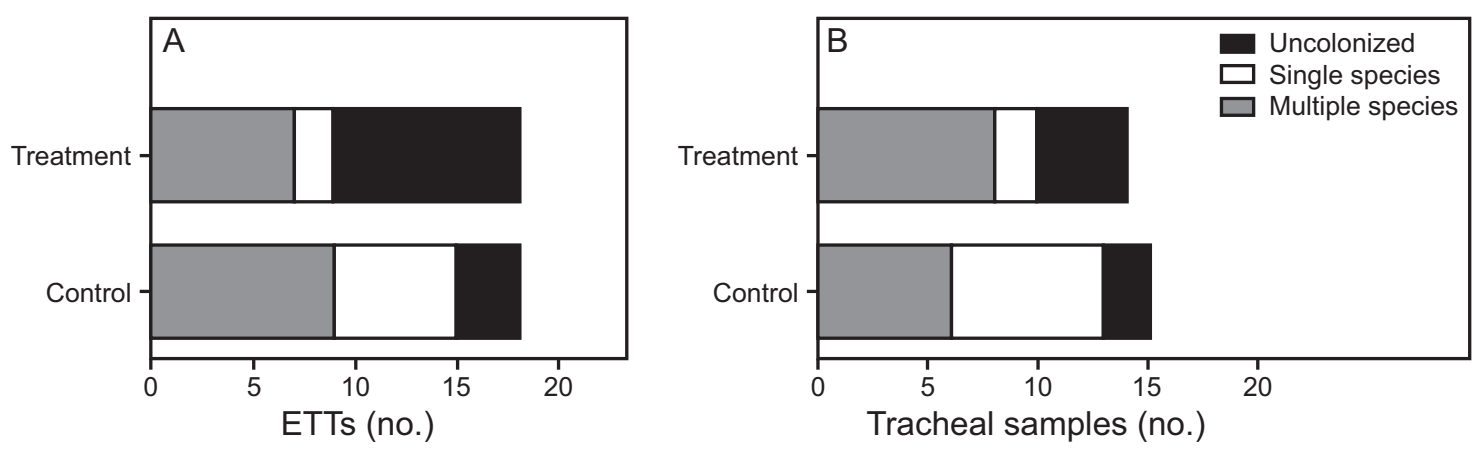

Fig. 2. Rates of (A) endotracheal tubes (ETTs) or (B) tracheal sputum microbial colonization by a single versus multiple species.

Table 3. Colonization of Tracheal Secretions

\begin{tabular}{lccc}
\hline \hline & Control & Treatment & $P$ \\
\hline Colonized secretions, no. $(\%)$ & $13(87)$ & $10(71)$ & .39 \\
$\quad$ Gram positive & $6(40)$ & $6(43)$ & $>.99$ \\
Gram negative & $1(7)$ & $2(14)$ & .60 \\
Yeasts & $11(73)$ & $7(50)$ & .26 \\
Multiple species present & $6(40)$ & $8(53)$ & .71 \\
Species isolated per sample, no. & $1.5 \pm 1.2$ & $1.6 \pm 1.6$ & .79 \\
Total microbial load, logCFU/mL & $4.8 \pm 4.0$ & $4.2 \pm 3.8$ & .70 \\
Gram positive, $\log$ CFU/mL & $0.5 \pm 0.6$ & $0.9 \pm 1.2$ & .27 \\
Gram negative, $\log$ CFU/mL & $0.1 \pm 0.5$ & $0.1 \pm 0.4$ & .95 \\
Yeasts, logCFU/mL & $0.9 \pm 0.2$ & $0.7 \pm 0.2$ & .46 \\
Colonized secretions, no. $(\%)$ & $13(87)$ & $10(71)$ & .39
\end{tabular}

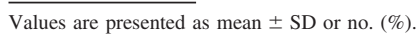

Control group, $n=15$ subjects; Treatment group, $n=14$ subjects.

Gram-positive species = Enterobacteriaceae, Corynebacterium spp., Staphylococcus aureus,

Staphylococcus spp., Streptococcus spp., Lactobacillum spp.

Gram-negative species = Escherichia coli, Enterobacter aerogenes, Klebsiella pneumoniae,

Pseudomonas fluorescens

Yeasts = Candida tropicalis, Candida albicans, Candida parapsilosis, Candida glabra

$\mathrm{CFU}=$ colony-forming unit

\section{Polymerase Chain Reaction and Electrospray Ionization Mass Spectrometry Analysis}

All of the 10 slices of ETT sent for culture-independent analysis with polymerase chain reaction (PCR) and electrospray ionization mass spectrometry (ESI-MS) tested positive for the presence of microbial genome, even in the 2 slices that did not yield positive microbial cultures (Table 4). In both cases, the subjects remained intubated for $3 \mathrm{~d}$. Yeasts were detected with PCR/ESI-MS in all ETTs that were positive in both culture-dependent and cultureindependent analysis. Tracheal tube flora was characterized by the presence of species from oral microbial flora (samples 28, 33, 35, 40). Confocal laser scanning microscopy/fluorescent in situ hybridization was performed on control group samples 33 and 41 and treatment group samples 31 and 32 (Fig. 3). Fungal growth was present in all 4 tubes that were analyzed (11.5 $\pm 3 \mathrm{~d}$ of intubation).
Gram-positive growth appeared to be influenced by the cleaning maneuver, with more mixed and spread bacterial colonies in the treatment group, in contrast to the separate and clumped colonies in the control group.

\section{Discussion}

In this pilot trial, we investigated whether mechanically removing secretions from the lumen of silver-coated ETTs affected bacterial colonization in the ETTs of subjects requiring in-hospital emergency intubation and expected to remain intubated for at least $48 \mathrm{~h}$. This randomized, controlled trial showed that, despite our best efforts to remove secretions from the lumen of silver-coated ETTs, bacterial and fungal colonization persisted in approximately $50 \%$ of ETTs. When ETTs were not internally cleaned (control group), silver-coated ETTs were colonized in $>80 \%$ of samples, with low total bacterial load $(1.6 \pm 1.2$ $\log \mathrm{CFU} / \mathrm{mL}$ ). Quantitative PCR showed the presence of bacterial DNA sequences even in those ETTs with negative cultures (Table 4). As a result, both control and treatment groups' tracheal secretions combined were colonized in $>70 \%$ of samples $(87 \%$ in the control group, $71 \%$ in the treatment group, $P=.39$ ).

The first study investigating the antibacterial properties of silver-coated ETTs was performed by Olson et al. ${ }^{11}$ Silver was incorporated into the polyvinylchloride of ETTs and tested in a ventilated canine model of pneumonia. The authors showed decreased concentration of Pseudomonas aeruginosa in the lung parenchyma of dogs assigned to be intubated with the silver-coated ETT. However, after a period of time, the lumen of the silver-coated ETTs became colonized by bacteria. Antiseptics and antimicrobials (silver, gold, platinum with or without sulfadazine, chlorhexidine, and ultraviolet light) have been shown to delay but do not eliminate bacterial colonization. ${ }^{12}$ In addition, due to the anti-adhesive properties of these coatings, accumulation of secretions on the ETT lumen was decreased compared to non-coated ETTs.

To optimize the clearance of secretions from the ETT lumen, Kolobow et al ${ }^{8,9}$ designed devices to wipe the sur- 
Table 4. Comparison Between PCR and Standard Culture on Silver-Coated Tubes

\begin{tabular}{|c|c|c|c|c|c|}
\hline & \multirow{2}{*}{ Test Tube } & \multicolumn{2}{|c|}{ Quantitative PCR } & \multicolumn{2}{|c|}{ Standard Culture } \\
\hline & & Microorganism & Quantity (genomes) & Microorganism & Quantity $(\log \mathrm{CFU} / \mathrm{mL})$ \\
\hline \multirow[t]{18}{*}{ Control } & 33 & Prevotella melaninogenica & 241 & Staphylococcus spp. & 2.2 \\
\hline & & Staphylococcus epidermidis & 71 & Lactobacillus spp. & 1 \\
\hline & & Candida glabrata & 18 & & \\
\hline & 35 & Candida glabrata & 22 & Staphylococcus spp. & 2.6 \\
\hline & & Corynebacterium striatum & 18 & Corynebacterium spp. & 1.3 \\
\hline & & Staphylococcus epidermidis & 14 & Escherichia coli & 1 \\
\hline & & Prevotella melaninogenica & 12 & & \\
\hline & 37 & Propionibacterium acnes & 3 & & \\
\hline & & Bordetella pertussis & 3 & & \\
\hline & & Moraxella osloensis & 2 & & \\
\hline & 40 & Candida glabrata & 119 & Staphylococcus spp. & 2.8 \\
\hline & & Staphylococcus epidermidis & 47 & Candida glabrata & 2.2 \\
\hline & & Prevotella oris & 34 & Enterobacter spp. & 1.8 \\
\hline & & Candida albicans & 16 & Corynebacterium spp. & 1.8 \\
\hline & & Campylobacter concisus & 11 & & \\
\hline & 41 & Klebsiella pneumoniae & 165 & Klebsiella spp. & 6.8 \\
\hline & & Candida glabrata & 122 & & \\
\hline & & Candida albicans & 12 & & \\
\hline \multirow[t]{16}{*}{ Treatment } & 28 & Candida albicans & 675 & Staphylococcus spp. & 2 \\
\hline & & Staphylococcus epidermidis & 200 & & \\
\hline & & Rothia mucilaginosa & 15 & & \\
\hline & 31 & Candida glabrata & 124 & Candida glabrata & 2.8 \\
\hline & & Staphylococcus epidermidis & 11 & Streptococcus spp. & 2 \\
\hline & 32 & Candida albicans & 119 & Candida parapsilosis & 1.6 \\
\hline & & Candida glabrata & 62 & Staphylococcus spp. & 1.3 \\
\hline & & Candida parapsilosis & 25 & Candida albicans & 1 \\
\hline & & Staphylococcus epidermidis & 12 & & \\
\hline & & Streptococcus agalactiae & 1 & & \\
\hline & 36 & Streptococcus sanguinis & 8 & & \\
\hline & & Methylobacterium zatmanii & 7 & & \\
\hline & 38 & Candida albicans & 148 & Candida albicans & 5.2 \\
\hline & & Staphylococcus aureus & 21 & Staphylococcus spp. & 3 \\
\hline & & Staphylococcus epidermidis & 1 & Staphylococcus aureus & 2.6 \\
\hline & & & & Moraxella spp. & 1 \\
\hline $\begin{array}{l}\mathrm{PCR}=\text { polyr } \\
\mathrm{CFU}=\text { color }\end{array}$ & $\begin{array}{l}\text { reaction } \\
\text { init }\end{array}$ & & & & \\
\hline
\end{tabular}

face of ETTs and devices to intermittently suction secretions to prevent secretion deposition. In a recent clinical trial in 74 critically ill subjects, Pinciroli et al ${ }^{18}$ showed that the use of a mechanical wiper to clean the lumen of standard non-coated ETTs reduced ETT-luminal mucus accumulation and decreased ETT-luminal narrowing, thus suggesting a possible decrease in the subject's work of breathing when compared to standard management of ETTs with closed system-suctioning (control group). However, despite the large amount of secretions retrieved from the ETT, bacterial and fungal colonization persisted in the cleaned ETT lumen. In addition, lower respiratory tract colonization did not differ between the treatment group and the control group.
The use of a cleaning device theoretically should prolong the antimicrobial activity of a coated ETT. In an experimental study in sheep that were mechanically ventilated for $>72 \mathrm{~h}$, a combination of silver sulfadiazine coating and the Mucus Shaver (Endoclear) showed reduced secretion accumulation on the ETT lumen and significantly reduced the incidence of ETT colonization. ${ }^{14}$ Similarly, in this study, we showed that silver-coated ETTs, when cleaned with a wiper, maintained very low levels of bacterial growth $(0.9 \pm 1.2 \log \mathrm{CFU} / \mathrm{mL})$ and secretion deposition within the ETT lumen (288.9 $\pm 157.7 \mathrm{mg})$. However, microbial colonization cannot be avoided, even when a wiper is used.

Two in vivo pilot studies reported an absence of bacterial growth from ETT surfaces coated with silver. ${ }^{24,25}$ How- 

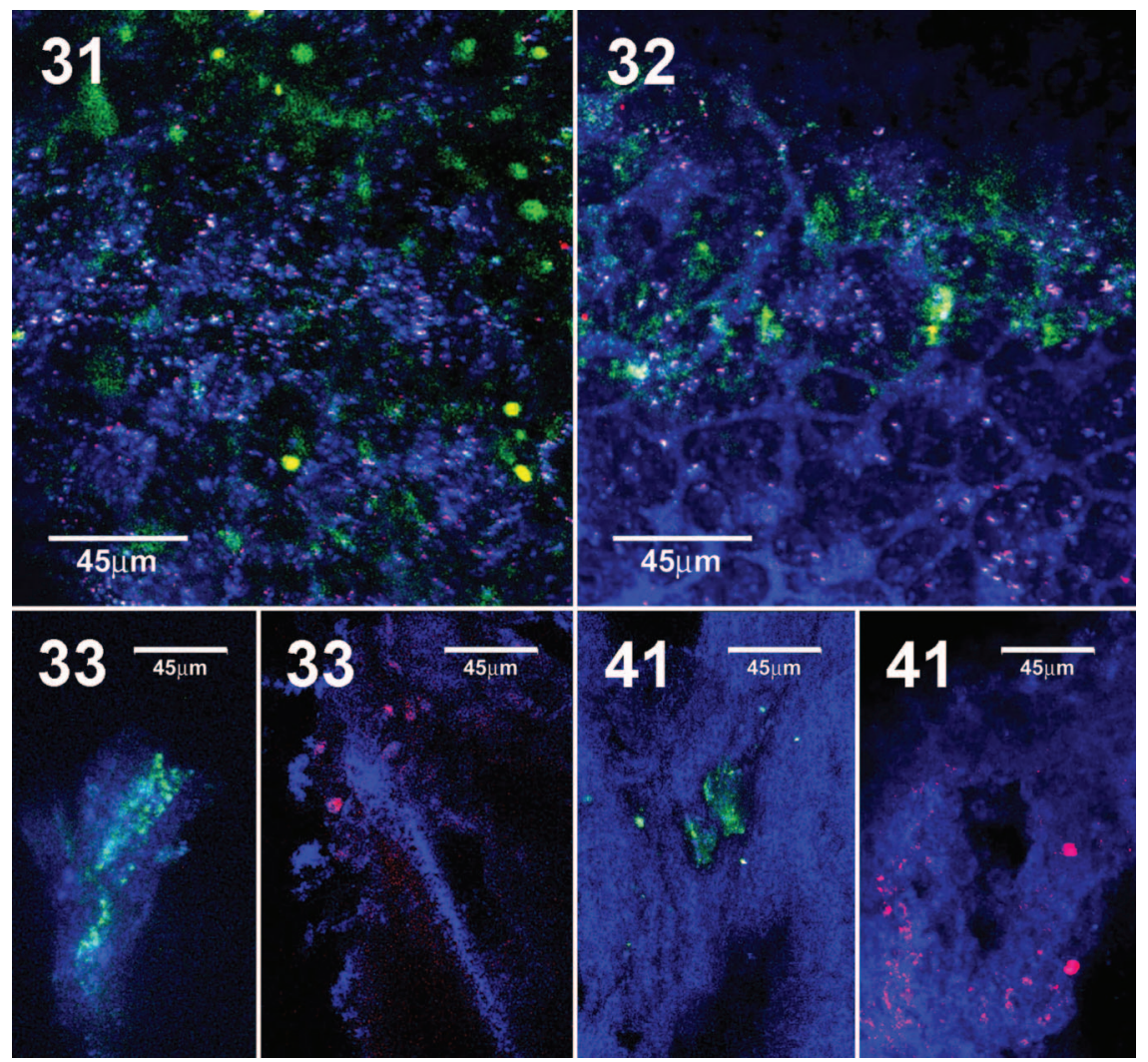

Fig. 3. Samples 31 and 32 are from ETTs from the control group. Sample 31 shows Candida glabrata (green) and Staphylococcus spp. (red). Sample 32 shows yeast (green) and Staphylococcus spp. (red). Samples 33 and 41 are from ETTs from the treatment group cleaned with the endOclear device. Sample 33 shows C. glabrata (green) and Staphylococcus spp. (red). Sample 41 shows C. glabrata (green) and Klebsiella pneumoniae (red).

ever, these studies failed to inactivate silver ions with sodium thioglycolate prior to determining bacterial growth ex vivo. To date, we are not aware of any studies that, after proper deactivation of silver ions with sodium thioglycolate, demonstrate prevention of pathogenic bacterial colonization in ETTs.

Cleaning of the ETT in this study did not prevent a higher level of colonization of the lower respiratory tract than that which occurred in the ETT. We speculate that the reason for this was silent aspiration of secretions past the cuff of the ETT. As noted in many recent studies, current cuff design and cuff inflation techniques do not prevent the movement of secretions past ETT cuffs. ${ }^{26-29}$ Intermittent inflation of cuffs does not minimize secretion movement past ETT cuffs, and continuous pressure regulation is necessary to minimize leakage. ${ }^{30-32}$ Unless better cuff designs and the use of continuous regulation of cuff pressure become standards of care, it is doubtful that simply minimizing intraluminal ETT secretion load will have a marked effect on tracheal colonization.

To interpret our data, however, one should consider the following limitations. First, the sample size was calculated to detect a $0.5-\log$ reduction (ie, $50 \%$ reduction) of bac- terial colonization on the coated ETT. It might be possible that a statistical difference might have been detected if a lower degree of reduction of bacterial colonization were used (thus, a much larger sample size). Although our study could be underpowered to detect a lower reduction of bacterial growth, the requirement of $>40$ subjects to detect a difference in ETT bacterial growth suggests that the intervention (coated ETT and cleaning) might not be as costeffective and clinically relevant as observed in prior experimental studies. ${ }^{8,12,14}$ Thus, the conclusions of this study are bound by the sample size.

Our primary end point selection was ETT bacterial colonization, as opposed to a relevant clinical outcome (eg, VAP incidence, duration of ventilation, mortality). This is an explorative bacteriological study aimed to assess the ability of airway devices to prevent a possible pathway of bacterial exposure to the lower respiratory tract, rather than a randomized, controlled trial on clinical outcome.

In conclusion, despite overall low levels of microbial colonization and negligible secretion deposits in the lumens of silver-coated ETTs, the use of a cleaning device failed to show a reduction of $>50 \%$ in bacterial coloni- 


\section{Secretion Removal in Silver-Coated ETTs}

zation of the ETT and did not translate into lower respiratory tract bacterial colonization compared to subjects with silver ETTs and a standard cleaning protocol $(4.8 \pm 4.0$ $\log \mathrm{CFU} / \mathrm{mL}$ in the control group, $4.2 \pm 3.8 \log \mathrm{CFU} / \mathrm{mL}$ in the treatment group, $P=.70$ ). These findings may suggest that, in addition to bacterial seeding of the lower respiratory tract through the ETT lumen itself, other pathogenic pathways contribute to pneumonia pathogenesis in intubated subjects.

At this time, it is unclear whether the combination of silver coating and cleaning devices may translate into a robust clinical benefit in large clinical trials. More experimental studies should explore the precise mechanisms of pneumonia formation in intubated subjects and whether prophylactic cleaning of intra-luminal ETT secretions and prevention of biofilm formation alone decreases colonization of the lower respiratory tract.

\section{REFERENCES}

1. Li Bassi G, Fernandez-Barat L, Saucedo L, Giunta V, Marti JD, Tavares Ranzani O, et al. Endoendotracheal tube biofilm translocation in the lateral Trendelenburg position. Crit Care 2015;19:59.

2. Danin PE, Girou E, Legrand P, Louis B, Fodil R, Christov C, et al. Description and microbiology of endotracheal tube biofilm in mechanically ventilated subjects. Respir Care 2015;60(1):21-29.

3. Pirrone M, Pinciroli R, Berra L. Microbiome, biofilms, and pneumonia in the ICU. Curr Opin Infect Dis 2016;29(2):160-166.

4. Gil-Perotin S, Ramirez P, Marti V, Sahuquillo JM, Gonzalez E, Calleja I, et al. Implications of endotracheal tube biofilm in ventilator-associated pneumonia response: a state of concept. Crit Care 2012;16(3):R93.

5. Mietto C, Pinciroli R, Piriyapatsom A, Thomas JG, Bry L, Delaney ML, et al. Tracheal tube obstruction in mechanically ventilated patients assessed by high-resolution computed tomography. Anesthesiology 2014;121(6):1226-1235.

6. Feldman C, Kassel M, Cantrell J, Kaka S, Morar R, Goolam Mahomed A, Philips JI. The presence and sequence of endotracheal tube colonization in patients undergoing mechanical ventilation. Eur Respir J 1999;13(3):546-551.

7. Inglis TJ, Millar MR, Jones JG, Robinson DA. Tracheal tube biofilm as a source of bacterial colonization of the lung. J Clin Microbiol 1989;27(9):2014-2018.

8. Kolobow T, Berra L, Li Bassi G, Curto F. Novel system for complete removal of secretions within the endotracheal tube: the Mucus Shaver. Anesthesiology 2005;102(5):1063-1065.

9. Kolobow T, Li Bassi G, Curto F, Zanella A. The Mucus Slurper: a novel endotracheal tube that requires no endotracheal tube suctioning. A preliminary report. Intensive Care Med 2006;32(9): 1414-1418.

10. Mann EE, Magin CM, Mettetal MR, May RM, Henry MM, DeLoid $\mathrm{H}$, et al. Micropatterned endotracheal tubes reduce secretion-related lumen occlusion. Ann Biomed Eng 2016;44(12):3645-3654.

11. Olson ME, Harmon BG, Kollef MH. Silver-coated endotracheal tubes associated with reduced bacterial burden in the lungs of mechanically ventilated dogs. Chest 2002;121(3):863-870.

12. Berra L, Curto F, Li Bassi G, Laquerriere P, Pitts B, Baccarelli A, Kolobow T. Antimicrobial-coated endotracheal tubes: an experimental study. Intensive Care Med 2008;34(6):1020-1029.

13. Kollef MH, Afessa B, Anzueto A, Veremakis C, Kerr KM, Margolis $\mathrm{BD}$, et al. Silver-coated endotracheal tubes and incidence of venti- lator-associated pneumonia: the NASCENT randomized trial. JAMA 2008;300(7):805-813.

14. Berra L, Curto F, Li Bassi G, Laquerriere P, Baccarelli A, Kolobow T. Antibacterial-coated endotracheal tubes cleaned with the Mucus Shaver: a novel method to retain long-term bactericidal activity of coated endotracheal tubes. Intensive Care Med 2006;32(6):888-893.

15. Bjorling G, Johansson D, Bergstrom L, Jalal S, Kohn I, Frostell C, Kalman S. Tolerability and performance of BIP endotracheal tubes with noble metal alloy coating: a randomized clinical evaluation study. BMC Anesthesiol 2015;15:174.

16. Jiang X, Wang Y, Hua J, Lyu B. [Study on antibacterial property of silver loaded titanium dioxide antibacterial coated endotracheal intubation tube]. Zhonghua Wei Zhong Bing Ji Jiu Yi Xue 2014;26(5): 343-346.

17. Mietto C, Foley K, Salerno L, Oleksak J, Pinciroli R, Goverman J, Berra L. Removal of endotracheal tube obstruction with a secretion clearance device. Respir Care 2014;59(9):e122-e126.

18. Pinciroli R, Mietto C, Piriyapatsom A, Chenelle CT, Thomas JG, Pirrone M, et al. Endotracheal tubes cleaned with a novel mechanism for secretion removal: a randomized controlled clinical study. Respir Care 2016;61(11):1431-1439.

19. Hellyer TP, Ewan V, Wilson P, Simpson AJ. The Intensive Care Society recommended bundle of interventions for the prevention of ventilator-associated pneumonia. J Intensive Care Soc 2016;17(3): 238-243.

20. Perez E, Williams M, Jacob JT, Reyes MD, Chernetsky Tejedor S, Steinberg JP, et al. Microbial biofilms on needleless connectors for central venous catheters: comparison of standard and silver-coated devices collected from patients in an acute care hospital. J Clin Microbiol 2014;52(3):823-831.

21. Berra L, De Marchi L, Yu ZX, Laquerriere P, Baccarelli A, Kolobow T. Endotracheal tubes coated with antiseptics decrease bacterial colonization of the ventilator circuits, lungs, and endotracheal tube. Anesthesiology 2004;100(6):1446-1456.

22. Hogardt M, Trebesius K, Geiger AM, Hornef M, Rosenecker J, Heesemann J. Specific and rapid detection by fluorescent in situ hybridization of bacteria in clinical samples obtained from cystic fibrosis patients. J Clin Microbiol 2000;38(2):818-825.

23. Waar K, Degener JE, van Luyn MJ, Harmsen HJ. Fluorescent in situ hybridization with specific DNA probes offers adequate detection of Enterococcus faecalis and Enterococcus faecium in clinical samples. J Med Microbiol 2005;54(Pt 10):937-944.

24. Rello J, Kollef M, Diaz E, Sandiumenge A, del Castillo Y, Corbella $\mathrm{X}$, Zachskorn R. Reduced burden of bacterial airway colonization with a novel silver-coated endotracheal tube in a randomized multiple-center feasibility study. Crit Care Med 2006;34(11):2766-2772.

25. Berra L, Kolobow T, Laquerriere P, Pitts B, Bramati S, Pohlmann J, et al. Internally coated endotracheal tubes with silver sulfadiazine in polyurethane to prevent bacterial colonization: a clinical trial. Intensive Care Med 2008;34(6):1030-1037.

26. Zanella A, Cressoni M, Epp M, Stylianou M, Kolobow T. A doublelayer endotracheal tube cuff designed to prevent leakage: a benchtop study. Intensive Care Med 2008;34(6):1145-1149.

27. Kolobow T, Cressoni M, Epp M, Corti I, Cadringher P, Zanella A. Comparison of a novel lycra endotracheal tube cuff to standard polyvinyl chloride cuff and polyurethane cuff for fluid leak prevention. Respir Care 2011;56(8):1095-1099.

28. Pitts R, Fisher D, Sulemanji D, Kratohvil J, Jiang Y, Kacmarek R. Variables affecting leakage past endotracheal tube cuffs: a bench study. Intensive Care Med 2010;36(12):2066-2073.

29. Young PJ, Rollinson M, Downward G, Henderson S. Leakage of fluid past the endotracheal tube cuff in a benchtop model. Br J Anaesth 1997;78(5):557-562. 


\section{Secretion Removal in Silver-Coated ETTs}

30. Monsel A, Le Corre M, Deransy R, Brisson H, Arbelot C, Lu Q, et al. Modification of tracheal cuff shape and continuous cuff pressure control to prevent microaspiration in an ex vivo pig tracheal two-lung model. Crit Care Med 2017;45(12):e1262-e1269.

31. Lorente L, Lecuona M, Jimenez A, Lorenzo L, Roca I, Cabrera J, et al. Continuous endotracheal tube cuff pressure control system protects against ventilator-associated pneumonia. Crit Care 2014; 18(2):R77.

32. Nseir S, Zerimech F, Fournier C, Lubret R, Ramon P, Durocher A, Balduyck M. Continuous control of tracheal cuff pressure and microaspiration of gastric contents in critically ill patients. Am J Respir Crit Care Med 2011;184(9):1041-1047.

This article is approved for Continuing Respiratory Care Education credit. For information and to obtain your CRCE

(free to AARC members) visit

www.rcjournal.com 